\title{
Development of sandwich panels combining fibre reinforced concrete layers and fibre reinforced polymer connectors. Part I: Conception and pull-out tests
}

\author{
Rodrigo Lameiras*, Joaquim Barros, Isabel B. Valente, Miguel Azenha \\ ISISE - Institute for Sustainability and Innovation in Structural Engineering, University of Minho, School of Engineering, Department of Civil Engineering, Campus de Azurém, \\ 4800-058 Guimarães, Portugal
}

\section{A R T I C L E I N F O}

\section{Article history:}

Available online 26 June 2013

\section{Keywords:}

Insulated panels

Load-bearing panels

Sandwich panels

Steel fibre reinforced self-compacting

concrete (SFRSCC)

Glass fibre reinforced polymer (GFRP)

Pull-out test

\begin{abstract}
A B S T R A C T
In this paper, an innovative and thermally efficient sandwich panel is proposed for the structural walls of a pre-fabricated modular housing system. Traditionally, sandwich concrete panels consist of reinforced concrete wythes as outer layers, polystyrene foam as core material and steel connectors. However, steel connectors are known to cause thermal bridges on the building envelope, with possible consequent occurrence of condensation and mould problems. Furthermore, the reduction/optimization of the thickness of conventionally reinforced concrete layers is frequently limited by minimum concrete cover requirements for the protection of the reinforcement from corrosion. To overcome these issues, the proposed sandwich panel comprises Glass Fibre Reinforced Polymer (GFRP) connectors and two thin layers of Steel Fibre Reinforced Self-Compacting Concrete (SFRSCC). This paper presents the material and structural concept of the proposed building system. Moreover, the feasibility of using the proposed connectors and SFRSCC on the outer wythes is experimentally investigated through a series of pull-out tests where failure modes and load capacity of the connections are analysed.
\end{abstract}

(c) 2013 Elsevier Ltd. All rights reserved.

\section{Introduction}

The main advantage of using sandwich panels in building construction is related to the structural and thermal efficiency that can be achieved with this technology. By putting together thin, stiff and ductile concrete wythes, with a thermally-efficient core material, it is possible to obtain lightweight panels that are energy efficient, and can be easily handled and erected. This kind of structural solution has been extensively applied in precast structural panels, which are known to provide adequate weather sheltering, protection against mechanical damage, vapour barrier, efficient acoustic performance and thermal insulation [1].

Traditionally, these sandwich panels adopt conventionally reinforced concrete layers and steel devices to establish the connection between them. Commonly used shear transfer devices include wire truss connectors, bent wire connectors, and solid zones of concrete penetrating the foam [2-5].

Due to their high thermal conductivity, the steel connectors cause thermal bridging effects on the building envelope that result in additional transmission losses, decreasing the thermal efficiency of the sandwich panel, and promoting the occurrence of

\footnotetext{
* Corresponding author. Tel.: +351 253510 200; fax: +351 253510217 .

E-mail address: rmlameiras@civil.uminho.pt (R. Lameiras).
}

condensation and mould problems [6]. The existence of these thermal bridges increases the building energy demand for heating and cooling, and thus their avoidance is an essential challenge to achieve more thermally/energetically efficient and sustainable buildings. According to previous research [7], the use of steel pin connectors that represent $0.08 \%$ of the sandwich panel area, can reduce the insulation performance ( $R$-value) of a wall up to $38 \%$. The same research also reports that a thermal performance reduction of $77 \%$ is expected when the connection between outer layers is made through $0.08 \%$ of steel pin connectors and $21.25 \%$ of solid concrete zones. With the steadily increasing cost of energy, the interest in having energetically efficient buildings is no longer limited to environmental sustainability aspects, broadening its justification to actual economic reasons.

The use of Glass Fibre-Reinforced Polymer (GFRP) bent bars as connectors in replacement of the traditional metal wire trusses was introduced by Salmon et al. [4]. Test results showed that the use of GFRP provided a high level of composite action and ensured thermal benefits similar to non-composite insulated sandwich wall panels. Following the same concept, the use of Carbon Fibre-Reinforced Polymer (CFRP) shear connection grids was introduced in the construction of sandwich wall panels in 2003 [8,9]. Nevertheless, both these alternative solutions have higher initial costs than those of traditional sandwich panels. In fact, the pultrusion 
manufacturing process of CFRP bars requires high cost specialized machinery, and carbon fibre is still expensive for the proposed application.

This paper proposes an innovative precast sandwich panel with suitable structural and thermal performance, devised as a fundamental part of a construction system for modular buildings. This system is intended to be cost competitive with focus on reduction of construction time and material optimization. The proposed sandwich panel for exterior bearing walls comprises GFRP connectors of controlled cost, and two thin outer wythes of Steel Fibre Reinforced Self-Compacting Concrete (SFRSCC).

The role of SFRSCC is related to the inherent benefits of using this material instead of concrete with conventional reinforcement. Firstly, it allows reducing the volume of concrete necessary to produce the external layers, since the requirement of minimum concrete cover for the reinforcements in conventional reinforced concrete structures is not applicable to SFRSCC elements [10]. So, more structurally efficient and lightweight elements can be obtained. Another advantage is related to the possibility of reducing non-value adding activities on the production line and the related labour costs. Specifically, SFRSCC technology eliminates the tasks of placing the reinforcement (mesh or bars), and compacting/levelling concrete, thus allowing easier standardization of the production tasks. Furthermore, since the proposed panels are supposed to constitute the building envelope, it should be ensured that the width of the cracks in these elements is small enough to satisfy requirements concerning serviceability (functionality and appearance) and durability of the structure. In this context, SFRSCC has several properties that makes it attractive: it generally presents high crack-width control capacity, ductility, impact resistance, and water tightness due to the fibre reinforcement mechanisms provided by fibres bridging the microcracks, and the relatively high content of fine constituents. Furthermore, the costs of maintenance derived from corrosion of conventionally reinforced concrete layers are suppressed, since corrosion effects in SFRSCC have been reported to be negligible or even non-existing if crack width is limited to $0.3 \mathrm{~mm}[11,12]$.

Different types of Fibre-Reinforced Polymer (FRP) connectors have been proposed by several researchers for reinforced/prestressed concrete sandwich panels [9,13-15], and some of them are even commercially available [16]. SFRSCC was also suggested as the material for sandwich panels, in which the connection between the concrete layers is assured by solid zones of concrete [17]. Nevertheless, the combination of SFRSCC panels with FRP connectors to obtain a sandwich panel that takes advantage of both materials is unknown at present phase, thus motivating the research reported herein.

This paper begins with a brief description of the proposed building system. Different types of GFRP laminates and candidate materials for the connectors are characterised, and their mechanical properties compared. Then, an experimental program of pull-out tests is reported, with assessment of the feasibility and relative effectiveness of the suggested connections between GFRP and SFRSCC. For a better understanding of the structural behaviour of the panels, the companion paper [18] centres efforts for assessing the best solutions for the geometry of the panel and arrangement of GFRP connectors, through parametric analyses. The parametric studies include both linear and nonlinear numerical analyses of the panel subjected to the combined action of axial loadings and wind pressure.

\section{Proposed building system}

The building system that is being developed is composed of prefabricated sandwich structural panels for both walls and slabs, which are connected to each other in situ. The idea is to develop a structural exterior wall system that incorporates all the installations (water, electrical, network and telephone connections), thermal insulation and finishes. The entire system is prefabricated at a plant and transported to the construction site, where the remaining tasks to be performed are placement of the panels and application of connections to foundations and adjacent elements. Even though this construction system can be deployed for multi-storey buildings, the research efforts are currently being centred in single-storey buildings.

The prefabricated structural sandwich panel comprising thinwalled SFRSCC is schematically shown in Fig. 1a, where the various components involved are identified, and a possible arrangement of connectors is indicated. This wall system acts as the primary load carrying component of the structure transferring the loads to the foundation of the structure. The single storey wall panels span vertically between foundations and floor/roof panels without the need for additional intermediate supports. Horizontal floor and roof panels shall behave as one-way slabs, continuously supported on the inner concrete layer of wall panels, as shown in Fig. 1b. This eliminates the need for beams and columns along exterior walls. The horizontal panels shall also act as diaphragms that transfer the lateral loads to the walls.

The horizontal joints connect floor and wall units. In the case of dwellings, the principal forces to be transferred are vertical loads from the roof. The connection methods to be employed in these joints can be grouting, bolting, welding or a combination of these techniques $[19,20]$. The authors suggest the use of bearing pads combined to grouting dowels projected from the wall panel and from the roof/slab members. If the slab is used with a composite concrete topping, the connection can also be achieved using dowels from the wall to the cast-in-place topping.

Continuous footings are used to support the lower surface of the wall. The connection between the panel and the corresponding footing can be made through cast-in-place grout, as suggested in Fig. 1b.

\subsection{Geometry of panels}

The maximum possible length and weight of a panel is determined based on handling, transportation and installation requirements. Its dimensions should be as large as possible to reduce costs by diminishing the number of panels needed and, consequently, the number of joints and connections required. The thicknesses of the SFRSCC layers are as thin as possible to withstand the imposed loads over its service life, while being thick enough to make viable connections between both concrete layers and between the panel itself and adjacent horizontal/vertical panels. The thickness of the insulation material is primarily tailored to meet the desirable thermal performance for the building envelope. However, this thickness can be also specified based on structural or even on constructive requirements, since it influences the flexural stiffness and capacity of the panel, and the core can be also used to accommodate other installations.

\subsection{Connections between the concrete layers}

The connection between the two SFRSCC layers of a sandwich panel is assured by discrete or continuous one-way GFRP connectors. While the continuous connectors extend along the full height or length of the panel, the discrete connectors have much lower length than the in-plane dimensions of the panels, and are strategically positioned to ensure optimised strength/stiffness benefits.

Since these connectors are the main load transfer mechanism between both SFRSCC layers, they must resist to the forces resulting from loadings to which the panel may be subjected. It should be noticed that, if the panels are stripped from the horizontal posi- 


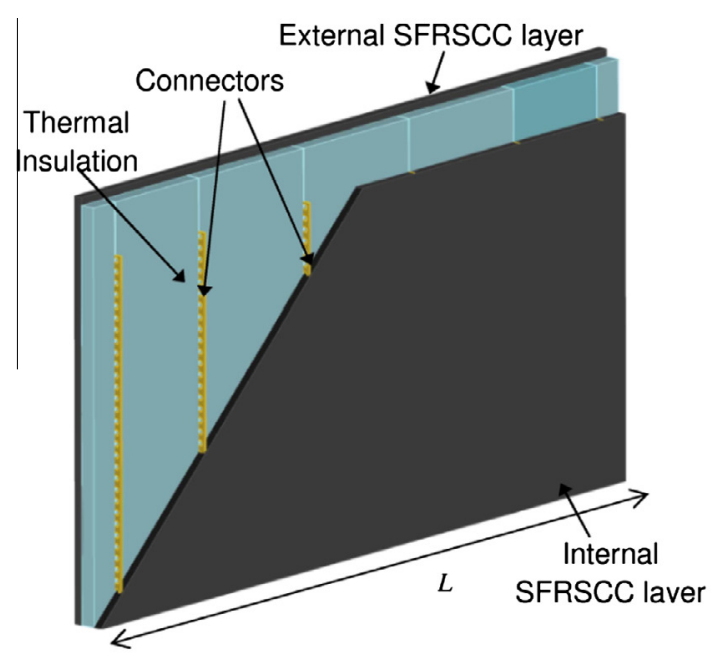

(a)

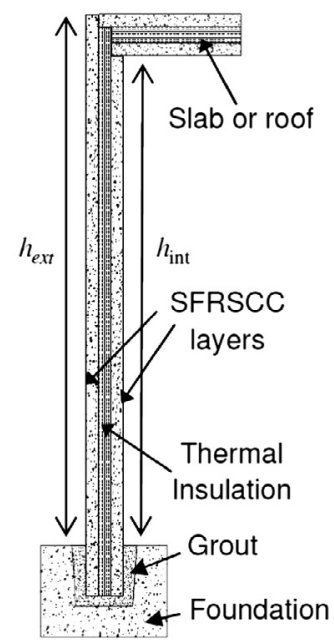

(b)

Fig. 1. Proposed building system: (a) components of the devised load-bearing sandwich wall panel and (b) system cross section.

tion, their connectors must be designed to resist the tensile forces caused by the self-weight of the lower wythe as well as the suction from the form generated during the lift up movement. Moreover, the connectors are also mobilized to transfer the shear stresses caused by flexural bending, as well as the in-plane stresses due to temperature variation and shrinkage.

For the GFRP-SFRSCC connection two main types of connectors are proposed, and herein evaluated: embedded (Fig. 2a and b) and adhesively bonded (Fig. 2c). The first ones are embedded into both concrete layers. Among the embedded connectors there are simply perforated plates (Fig. 2a) and connectors with a profiled shape (Fig. 2b). The simply perforated plates consist of a GFRP plate with a number of uniformly spaced holes, through which SFRSCC can flow (see Fig. 9b). During casting, the openings in the GFRP promote the formation of SFRSCC dowels, which increase the mechanical anchorage between the GFRP connector and the SFRSCC layer, providing shear resistance along the connector alignment and preventing the separation between the SFRSCC layers in the direction orthogonal to their planes. The second embedded profiled connector (Fig. 2b) consists of a I-shaped GFRP that is embedded into concrete, and the mechanical interlock provides the anchorage of the connector. When submitted to shear loading, the flanges of the Ishaped connector presents frontal bearing strength and the I web resists to shear stresses. These connectors are similar to the steel Perfobond and I-shaped connectors adopted in steel-concrete composite structural elements [21]. GFRP connectors similar to the simply perforated plates [22] and I-shaped [23] have already been proposed for hybrid GFRP-concrete bridge decks.

An alternative to the embedded connectors is the adoption of adhesively bonded connections, where the SFRSCC layers, the GFRP profiles and the thermal insulation blocks are connected by an adhesive joint (see Fig. 2c). Adhesive bonding is a connection method that has been extensively used in repair and strengthening of concrete structures for more than a decade [24]. This technique has been proposed for application in some FRP-concrete composite structures, especially in bridge decks $[25,26]$. The main benefit commonly associated to this technique is the assurance of a rather uniform stress distribution over the section of the composite structure, unlike the case of embedded connectors, which favour the occurrence of zones of high stress gradients [27]. As shown in Fig. 2c, the adhesive is spread in the entire surface of the panel. However, due to practical and economical restraints, a simpler alternative can be considered, which consists in spreading the adhesive layer only in the flanges of the I-profiles whereas the insulation plates could be connected through a male-female connection.

\section{Manufacture of the proposed panel}

\subsection{Panels comprising embedded connectors}

Traditionally, the construction of sandwich reinforced concrete panels is made by cutting, bending, tying and placing the reinforcement; pouring the first concrete wythe, followed by the placement of the thermal insulation blocks and of the connectors prior the concrete set time. Then, reinforcing steel and lifting inserts are placed and, finally, the panel is finished by pouring the second concrete wythe. However, if this traditional construction system was adopted by simply replacing the conventional concrete by the SFRSCC, the probability of obtaining fibres passing through the

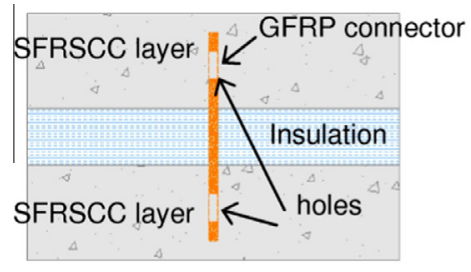

(a)

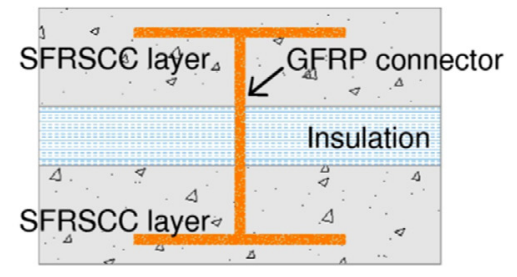

(b)

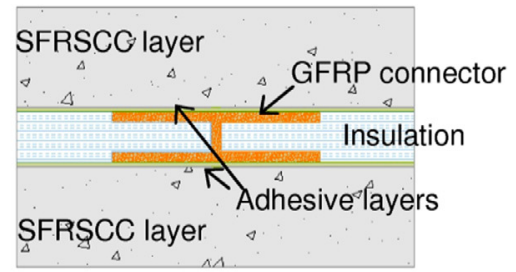

(c)

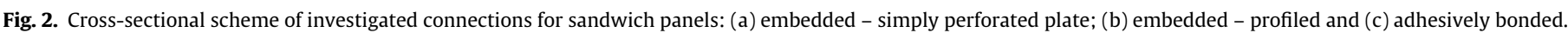


holes of the perforated GFRP plate connector would be reduced, since the connectors are positioned after the casting of the first SFRSCC layer. So, to overcome this limitation of the traditional system, particularly in the case of using perforated GFRP connectors, a new manufacturing system is proposed that permits the steel fibres to flow through the holes of the connectors. This system is described in the following paragraph and is schematically represented in Fig. 3.

A sandwich panel is cast on a planar formwork system that includes four slidable members. The overall thickness of the sandwich panel is achieved by adjusting the height of these members. Once the dimensions of the panel are configured, the connectors

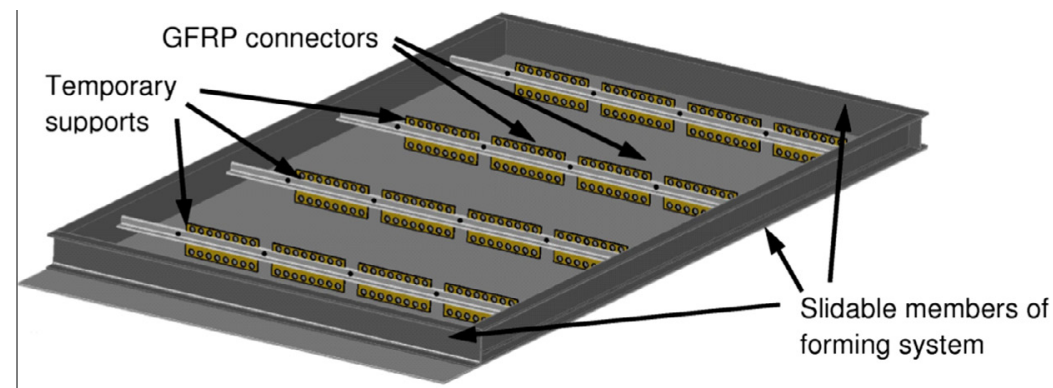

(a)

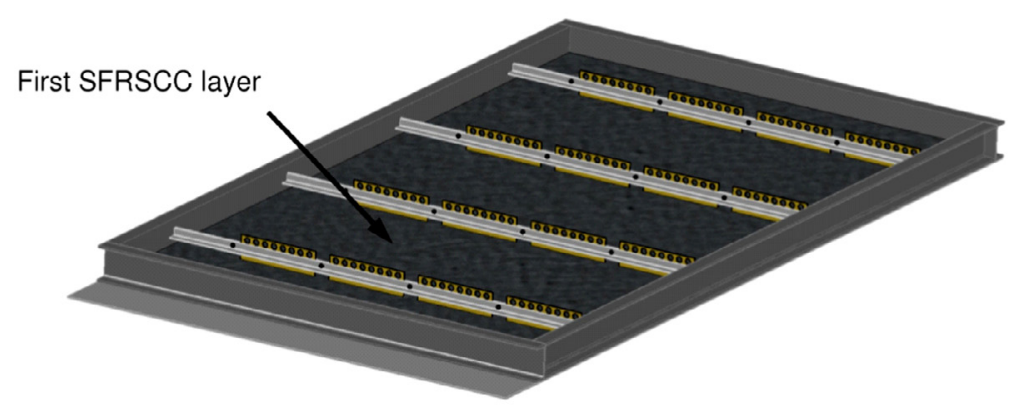

(b)

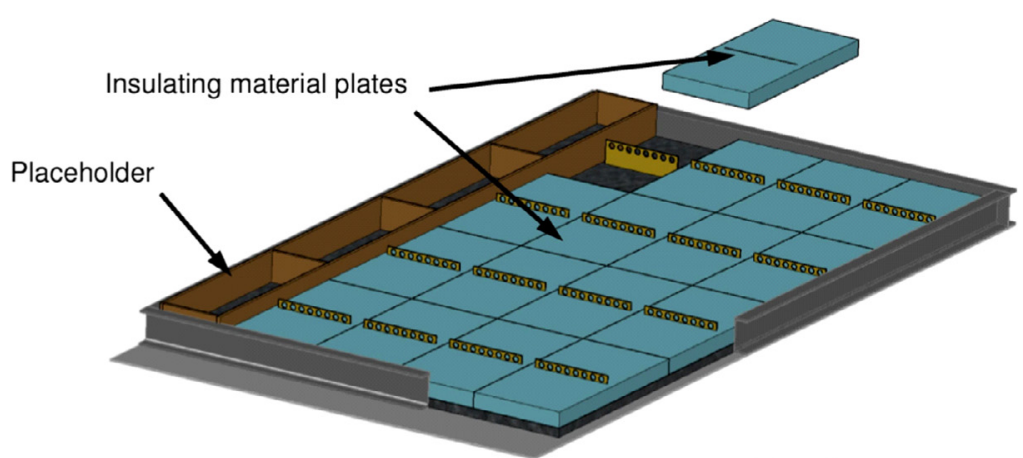

(c)

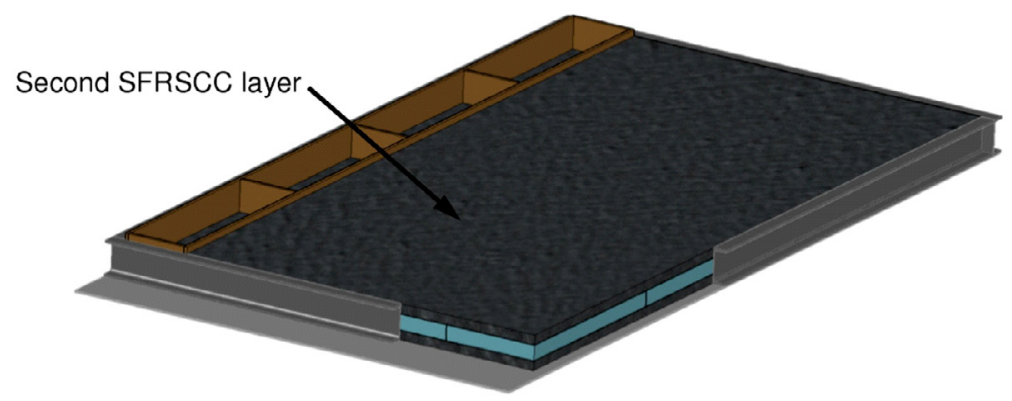

(d)

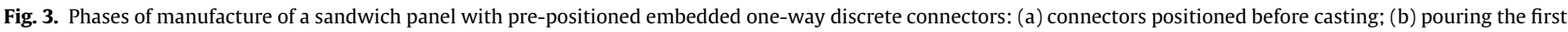
SFRSCC layer; (c) positioning the insulating material plates; (d) pouring the second SFRSCC layer. 
Table 1

Mix proportion for $1 \mathrm{~m}^{3}$ of SFRSCC.

\begin{tabular}{ll}
\hline Material & Quantity \\
\hline Cement $(\mathrm{kg})$ & 412.2 \\
Limestone filler $(\mathrm{kg})$ & 353.4 \\
Superplasticizer $\left(\mathrm{dm}^{3}\right)$ & 7.8 \\
Water $(\mathrm{kg})$ & 124.5 \\
Fine river sand $(\mathrm{kg})$ & 179.4 \\
Coarse river sand $(\mathrm{kg})$ & 654.6 \\
Crushed granite 5-12 mm (kg) & 588.0 \\
Hooked ends steel fibres $(\mathrm{kg})$ & 60.0 \\
\hline
\end{tabular}

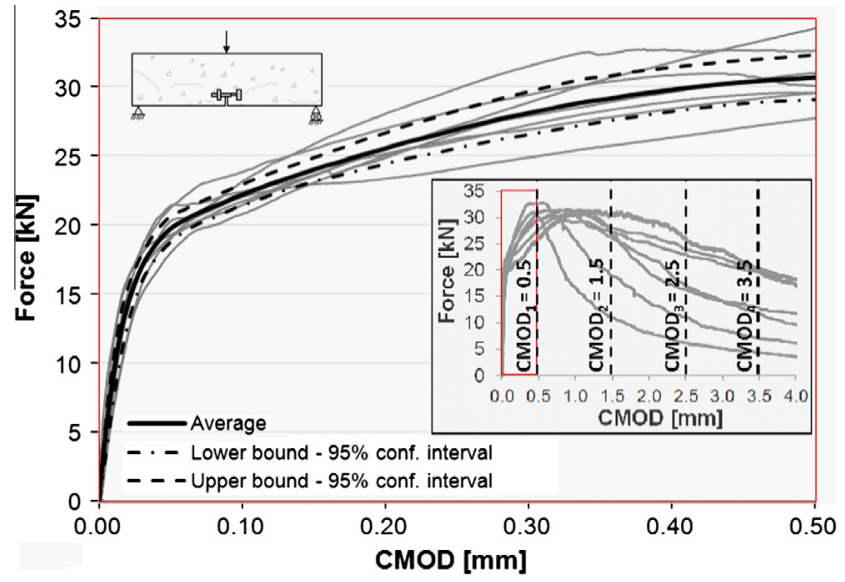

Fig. 4. Load-CMOD curves obtained in the three point notched SFRSCC beam bending tests.

are positioned and held firmly in position with the aid of temporary supports (see Fig. 3a). Then, the first layer of SFRSCC mix is poured into the panel form (see Fig. 3b). At this stage, the bottom perforated part of the connectors becomes submerged to the SFRSCC layer. Afterwards, while the first concrete layer hardens, insulating material plates are placed on top of the first concrete layer. In order to make the inner SFRSCC layer have a shorter height than the outer layer (see Fig. 1b), placeholders are used according to the scheme of Fig. 3c. These placeholders can also be used to materialise openings, such as windows and doors. After putting all of the insulating blocks on the top of the first SFRSCC layer, handling inserts and/or plate inserts are installed above the insulating blocks for the connection of these panels to the roof/floor elements. Later, the SFRSCC mix is poured, thus materialising the second SFRSCC layer (Fig. 3d). After initial curing, the panel is removed from the mould and stocked.

\subsection{Panels comprising adhesively bonded connectors}

The main difference on the manufacturing process of adhesively bonded panels is that the assemblage of panels is done independently of the concrete layers casting process. Firstly, both SFRSCC layers are cast in completely equal conditions. After the concrete curing time, the adhesive layer is spread in the proper surfaces of the concrete layers, and the panel is assembled by putting the thermal insulation foam and the GFRP profiles in their position.

Despite the practicality of using embedded connectors, such technique requires a minimum concrete thickness to ensure the effectiveness of the connection. The use of adhesively bonded connections allows overcoming this limitation with the advantage of obtaining two smooth surfaces (surfaces in contact to the mould) turned to the inner and outer side of building. On the other hand, a limitation of this technique is related to the number of stages and timeouts, namely the time required to cure the SFRSCC layers and the adhesive, with the consequent delay to join the parts together. Another potential problem related to this technology is the possibility of warping of the SFRSCC layers during stripping and handling before assembling the panel.

\section{Panel components: material properties and interaction}

\subsection{SFRSCC layers}

In this work, both concrete layers are made of a self-compacting concrete reinforced with $60 \mathrm{~kg} / \mathrm{m}^{3}$ of steel fibres. The materials used in the composition of SFRSCC are: cement CEM I 45.5R, limestone filler, third generation superplasticizer based on polycarboxylates, water, three types of aggregates (fine river sand, coarse river sand and crushed granite 5-12 mm) and hooked ends steel fibres of $35 \mathrm{~mm}$ length, $0.55 \mathrm{~mm}$ diameter and $1100 \mathrm{MPa}$ tensile strength. A rational method for conceiving the SFRSCC composition was adopted, based on the three following steps: (i) the proportions of the constituent materials of the binder paste are defined; (ii) the proportions of each aggregate on the final solid skeleton are determined; (iii) the proportions of binder paste and solid skeleton are optimised in order to assure the self-compacting requirements in terms of spread ability, filling ability and segregation resistance. This design strategy is described in detail elsewhere [28]. The mix proportions of the SFRSCC are given in Table 1. Immediately after mixing, fresh concrete mixture properties were evaluated by executing slump flow test with Abrams cone in the inverted position. A mean spread of $630 \mathrm{~mm}$ was measured and the mixture showed good homogeneity and cohesion.

Cylinders and prismatic specimens were cast to characterise the mechanical behaviour of SFRSCC. To assess the uniaxial compressive behaviour, six standard cylinders with $150 \mathrm{~mm}$ diameter and

Table 2

Results of the three point notched SFRSCC beam bending tests.

\begin{tabular}{|c|c|c|c|c|c|c|c|c|}
\hline \multirow[t]{2}{*}{ Specimen } & \multirow[t]{2}{*}{$f_{f c t, L}\left(\mathrm{~N} / \mathrm{mm}^{2}\right)$} & \multirow[t]{2}{*}{$f_{c t} 0.7 \cdot f_{f c t, L}\left(\mathrm{~N} / \mathrm{mm}^{2}\right)$} & \multicolumn{2}{|c|}{ Equivalent flexural tensile strength } & \multicolumn{4}{|c|}{ Residual flexural tensile strength } \\
\hline & & & $f_{e q, 2}\left(\mathrm{~N} / \mathrm{mm}^{2}\right)$ & $f_{e q, 3}\left(\mathrm{~N} / \mathrm{mm}^{2}\right)$ & $f_{R, 1}\left(\mathrm{~N} / \mathrm{mm}^{2}\right)$ & $f_{R, 2}\left(\mathrm{~N} / \mathrm{mm}^{2}\right)$ & $f_{R, 3}\left(\mathrm{~N} / \mathrm{mm}^{2}\right)$ & $f_{R, 4}\left(\mathrm{~N} / \mathrm{mm}^{2}\right)$ \\
\hline 1 & 6.77 & 4.74 & 9.19 & 4.29 & 9.64 & 3.54 & 1.97 & 1.40 \\
\hline 2 & 6.47 & 4.53 & 10.42 & 6.12 & 10.43 & 6.05 & 3.56 & 2.25 \\
\hline 3 & 6.16 & 4.31 & 9.48 & 8.37 & 9.46 & 8.72 & 7.37 & 6.30 \\
\hline 4 & 6.10 & 4.27 & 9.52 & 8.69 & 9.44 & 8.95 & 7.69 & 6.52 \\
\hline 5 & 5.73 & 4.01 & 9.86 & 7.67 & 9.90 & 8.37 & 5.47 & 3.80 \\
\hline 6 & 6.05 & 4.24 & 9.00 & 8.76 & 8.84 & 8.61 & 5.23 & 4.12 \\
\hline 7 & 6.84 & 4.79 & 10.89 & 10.86 & 10.93 & 12.71 & 9.24 & 6.87 \\
\hline Average & 6.30 & 4.41 & 9.77 & 7.62 & 9.81 & 8.13 & 5.79 & 4.46 \\
\hline L. bound ${ }^{*}$ & 6.00 & 4.20 & 9.26 & 6.26 & 9.29 & 6.05 & 3.93 & 2.86 \\
\hline U. bound & 6.61 & 4.62 & 10.27 & 9.38 & 10.32 & 10.22 & 7.65 & 6.07 \\
\hline
\end{tabular}

\footnotetext{
Values considering a level of confidence of $95 \%$.
} 
$300 \mathrm{~mm}$ height were tested [29]. An average compressive strength of $69.25 \mathrm{MPa}$ at 28 days was obtained with a standard deviation of $2.73 \mathrm{MPa}$. The modulus of elasticity of SFRSCC was determined by tests performed with five standard cylinders, and the mean value of $35.45 \mathrm{GPa}$ was obtained at 28 days with a standard deviation of 2.05 GPa [30]. The flexural behaviour of the SFRSCC was assessed by using seven $150 \times 150 \times 600 \mathrm{~mm}$ notched beams under three point bending tests at 28 days. The position and dimensions of the notch sawn into the specimens, the loading and specimen support conditions, the characteristics for both equipment and measuring devices, and the test procedures were those recommended by RILEM TC 162-TDF [31]. The obtained load vs crack mouth opening displacement (CMOD) curves are depicted in Fig. 4, and a set of relevant results is presented in Table 2 . Based on the force values for the $\mathrm{CMOD}_{i}(i=1-4$, see Fig. 4$)$ the corresponding force values, $F_{i}$, are obtained, and the derived residual flexural tensile strength parameters are determined from the following equation:

$f_{R, i}=\frac{3 F_{i} L}{2 b h_{s p}^{2}}$

where $f_{R, i}\left(\mathrm{~N} / \mathrm{mm}^{2}\right)$ and $F_{i}(\mathrm{~N})$ are, respectively, the residual flexural tensile strength and the force corresponding to $C M O D=C M O D_{i}$ $(\mathrm{mm}), b(=150 \mathrm{~mm})$ and $L(=500 \mathrm{~mm})$ are the width and the span of the specimen, and $h_{s p}(=125 \mathrm{~mm})$ is the distance between the tip of the notch and the top of the cross section. The concept of equivalent flexural tensile strength parameters $\left(f_{\text {eq, } 2}, f_{\text {eq, } 3}\right)$ proposed by RILEM TC 162-TDF [31] is similar to $f_{R i}$, but instead of a force for a certain CMOD, it considers the energy consumed (area under the F-CMOD curve) up to the aforementioned CMOD values or corresponding deflections (in case of measuring the deflection instead of CMOD).

Regarding the parameters related to the post-cracking behaviour $\left(f_{e q, 2}, f_{e q, 3}, f_{R, 1}, f_{R, 2}, f_{R, 3}\right.$ and $\left.f_{R, 2}\right)$, the authors are aware that the representativeness of the results obtained with the standard beam specimens for thin elements is questionable, once the fibre dispersion and orientation is strongly affected by the casting procedure and the elements geometry. However, the results obtained provide a general idea of the post-cracking resistance of the SFRSCC proposed for the outer layers of the panels. Furthermore, due to the geometry and casting conditions of the panel concrete layers, the fibre distribution tends to be predominantly parallel to the panel's plane, while in the RILEM standard beams the fibres have a 3D random distribution character. So, the effectiveness of fibre reinforcement is underestimated when the concrete is characterised by standard beams. Therefore, using the values from these tests the numerical model tends to be in favour of security (i.e.: conservative).

\subsection{GFRP connectors}

In the beginning of this research, the aim was to obtain and evaluate different types of GFRP laminates, with the lower cost possible, and that could be used to produce the connectors. At that moment, it was not clear which combination of fibres or connector thickness were the most appropriate to fulfill the wall panel requirements. Therefore, different combination of fibres and thicknesses were defined, in order to propose options that could provide various shear connection performance levels.

Four different types of GFRP were chosen as material candidates for the adopted connectors: (C1) a quasi-isotropic laminate

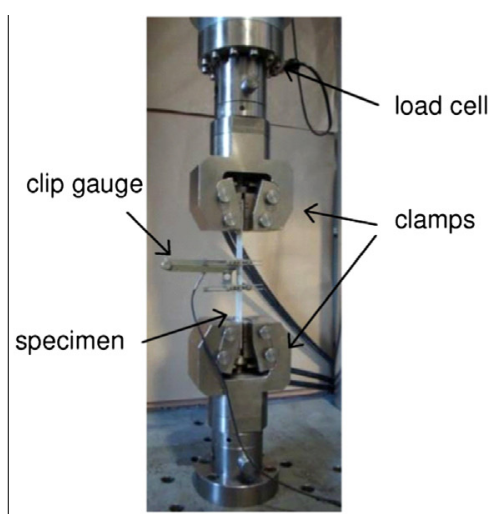

(a)

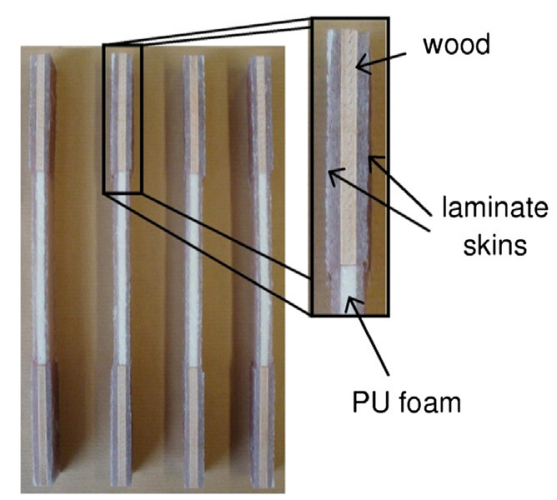

(c)

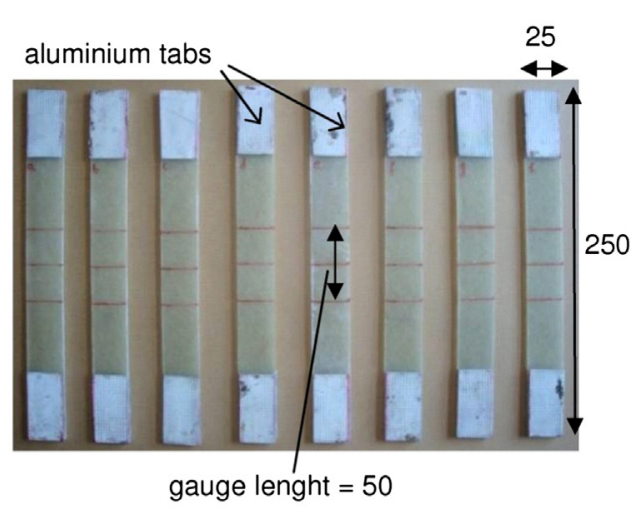

(b)
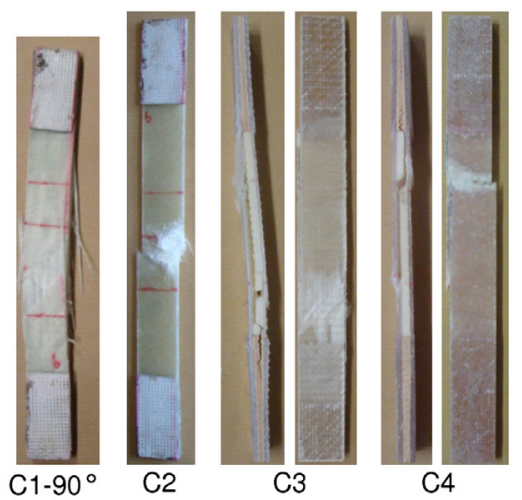

(d)

Fig. 5. Direct tensile tests on GFRP laminates: (a) test setup; (b) C2 tested specimens; (c) detail of the C4 specimens; and (d) ruptured specimens (units in millimetres). 
Table 3

Mechanical properties of different GFRPs under direct tensile tests.

\begin{tabular}{|c|c|c|c|c|c|c|c|}
\hline \multirow[t]{2}{*}{ GFRP type } & \multirow[t]{2}{*}{ Number of specimens } & \multicolumn{2}{|c|}{ Ultimate tensile strength $\left(\sigma_{p t}\right)(\mathrm{MPa})$} & \multicolumn{2}{|c|}{ Ultimate tensile strain $\left(\varepsilon_{p u}\right)(\mu \mathrm{m} / \mathrm{m})$} & \multicolumn{2}{|c|}{ Tensile modulus of elasticity $^{*}\left(E_{p t}\right)(\mathrm{GPa})$} \\
\hline & & Average & St. dev. & Average & St. dev. & Average & St. Dev. \\
\hline Quasi laminate $0^{\circ}$ & 5 & 363.4 & 17.2 & 26185.1 & 1982.1 & 14.30 & 0.32 \\
\hline Quasi laminate $90^{\circ}$ & 6 & 350.1 & 12.8 & 25912.3 & 1501.2 & 13.52 & 0.27 \\
\hline CSM laminate & 8 & 202.0 & 8.8 & 17881.4 & 969.0 & 12.65 & 0.47 \\
\hline Quasi sandwich & 4 & 194.7 & 5.4 & 21910.9 & 2732.1 & 9.51 & 0.24 \\
\hline CSM sandwich & 4 & 100.8 & 2.9 & 16462.4 & 1912.5 & 6.89 & 0.41 \\
\hline
\end{tabular}

In the case of the sandwich composites, the computed tensile modulus of elasticity corresponds to a stress-strain proportionality constant, since two different materials are involved.

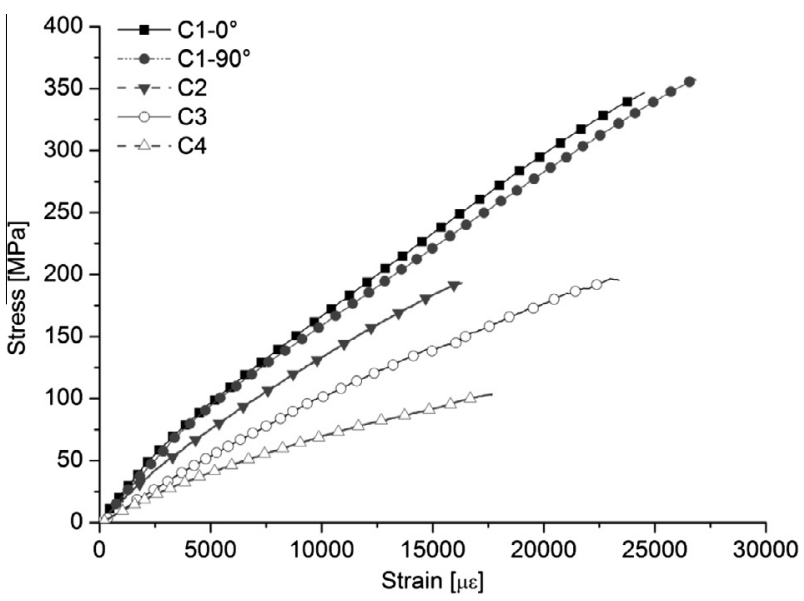

Fig. 6. Representative tensile stress-strain curves from direct tensile tests with GFRP specimens.

(hereinafter referred to as Quasi laminate), with $5 \mathrm{~mm}$ of thickness, obtained by stacking 6 sheets of a mat consisting of continuous Eglass fibres. Each sheet of this laminate comprises: $300 \mathrm{~g} / \mathrm{m}^{2}$ in the direction $0^{\circ}$ (longitudinal direction of connector), $297 \mathrm{~g} / \mathrm{m}^{2}$ of fibres in the direction $90^{\circ}$ (transversal direction of connector), $303 \mathrm{~g} / \mathrm{m}^{2}$ of fibres in the direction $+45^{\circ}$ and $303 \mathrm{~g} / \mathrm{m}^{2}$ of fibres in the direction $-45^{\circ}$ (for a better understanding of the fibre directions, see Fig. 8); (C2) a laminate with $2.5 \mathrm{~mm}$ of thickness, comprising 6 layers of a chopped strand mat (CSM) consisting of $500 \mathrm{~g} / \mathrm{m}^{2}$ of E-glass fibres (hereinafter referred to as CSM laminate); (C3) a sandwich composite consisting of $5 \mathrm{~mm}$ of polyurethane foam (PU foam) of density $35 \mathrm{~kg} / \mathrm{m}^{3}$ as core material, and 2 outer skins laminates, each one produced by stacking 2 sheets of the same mat adopted in the production of the Quasi laminate, providing a sandwich with $1.4 \mathrm{~mm}+5 \mathrm{~mm}+1.4 \mathrm{~mm}=7.8 \mathrm{~mm}$ of thickness (this material is hereinafter referred to as Quasi sandwich composite); and (C4) a sandwich composite with the same arrangement of the Quasi sandwich composite, but replacing the quasi-isotropic mat consisted of continuous fibres by the same CSM mat adopted in the manufacturing of the CSM laminate, totalling a laminate with: $2 \mathrm{~mm}+5 \mathrm{~mm}+2 \mathrm{~mm}=9 \mathrm{~mm}$ of thickness (in this paper it is referred to as CSM sandwich composite).

The Quasi laminate (C1) was chosen because it is the GFRP adopted in the connectors of a preliminary research performed by the authors [32]. The arrangements $\mathrm{C} 2-\mathrm{C} 4$ for the connectors are an attempt to reduce the costs, by adopting a mat with a lower cost (the case of CSM), or by reducing the content of the more expensive component (i.e.: reducing the number of layers of E-glass mat in the sandwiched solutions). The sandwich composites (C3 and C4) were the most competitive solutions to avoid instability derived from using thin laminates. In these composites the core material increases the internal arm of the resisting external layers, leading to an increase of the flexural stiffness of the sandwich composite without substantial increment in weight and cost of the final product.

All these GFRPs were manufactured by Vacuum Assisted Resin Transfer Moulding (VARTM) process [33]. The option for the VARTM process is justified by its relatively low cost, which allows obtaining parts with reduced dimensional variations through a highly automated process. All the GFRPs have a polyester resin matrix, due to its low cost and because it is one of the most common thermosetting resins used in the reinforced plastics.

For the determination of the mechanical properties of the composites, direct tensile tests under constant head-speed rate of $2 \mathrm{~mm} / \mathrm{min}$ were executed. In the case of the laminate $\mathrm{C} 1$, in which the content of fibre is slightly different in the different directions, tests were carried out loading the laminate in tension along the $0^{\circ}$ and $90^{\circ}$ fibre directions (hereafter called $\mathrm{C} 1-0^{\circ}$ and $\mathrm{C} 1-90^{\circ}$, respectively). On the other hand, the laminate $\mathrm{C} 3$ was tested only along the $90^{\circ}$ direction.

Plates were manufactured using the same process that was chosen for the connectors' production, and test specimens were cut from the flat plate using a diamond saw wheel. The specimens were $25 \mathrm{~mm}$ wide, and with the exception of the quasi laminates, the specimens were $250 \mathrm{~mm}$ long. In the case of the quasi laminates, the specimens were $280 \mathrm{~mm}$ long for the $0^{\circ}$ direction and $205 \mathrm{~mm}$ long for the $90^{\circ}$ direction. The test procedures described in ASTM D3039 [34] were followed, and tensile strength, stiffness and stress-strain relationship up to failure were determined. A clip-gauge with reference length of $50 \mathrm{~mm}$, fixed in the middle of each specimen, was used to measure the strain in the longitudinal direction (see Fig. 5a). To provide appropriate anchorage during testing and to diffuse the clamping stresses, rectangular aluminium tabs ( $50 \mathrm{~mm} \times 25 \mathrm{~mm} \times 1 \mathrm{~mm}$ ) were bonded at the extremities of the laminate specimens, as shown in the Fig. 5b. In the case of the sandwich composites the thickness of each laminate skin was increased to $3 \mathrm{~mm}$ in the extremities of the specimens to avoid gripping damage. In the extremities of these specimens the polyurethane foam was replaced by a wood plate to prevent premature failure, as result of crushing the foam in the region where the specimen is gripped by the clamps (Fig. 5c). All the tested specimens presented failures in the measuring gage region. During the tests with sandwich composites, a premature delamination of the specimens between the foam and the laminate skin was verified prior to the failure of the skin laminates. Representative failure modes for each type of composite can be observed in Fig. $5 \mathrm{~d}$. The tensile stresses of the laminate specimens were calculated for each data point simply dividing the registered force by the average crosssectional area of specimen. For the sandwich composites the tensile stresses were computed only considering the contribution of the laminate skins, disregarding the sectional area of the foam. The direct tensile test results are presented in Table 3 and representative results of the tensile stress strain curves obtained for the several types of GFRP are shown in Fig. 6. It is further remarked that each representative curve fairly matches the average behaviour, and that 


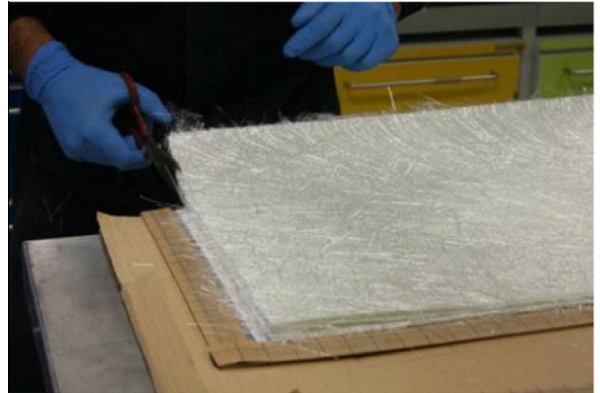

(a)

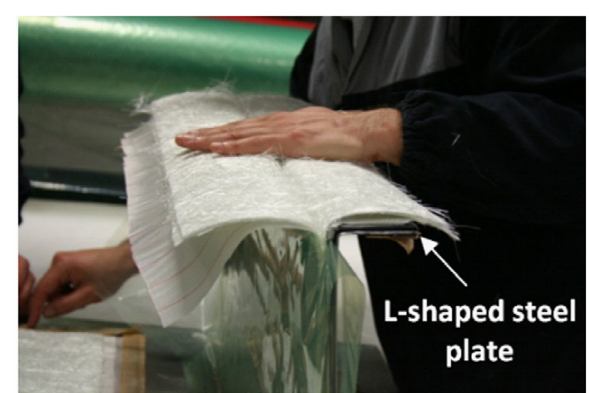

(b)

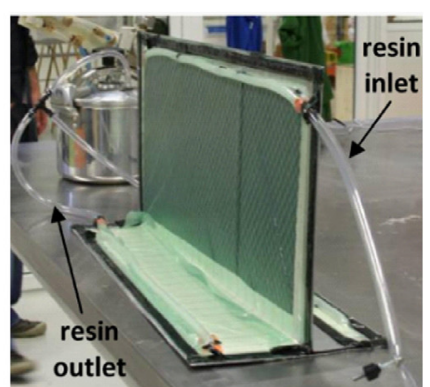

(c)

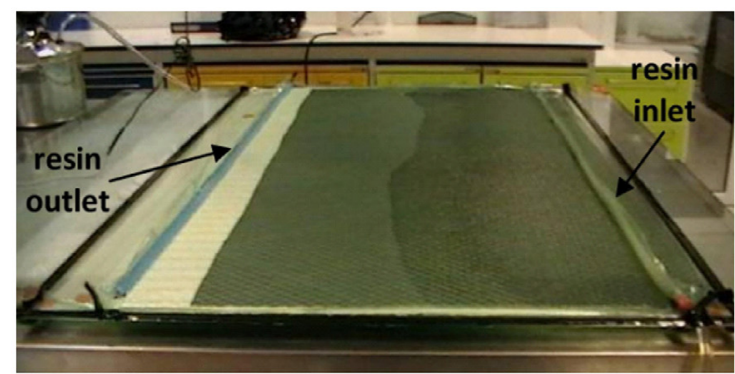

(d)

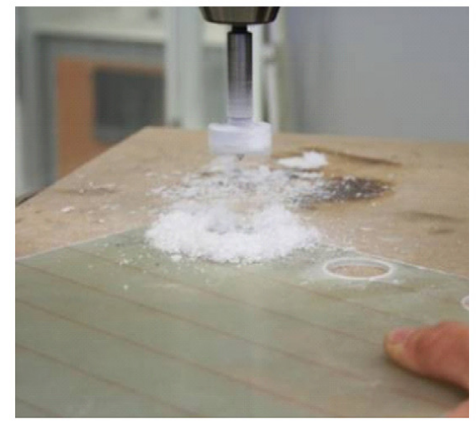

(e)

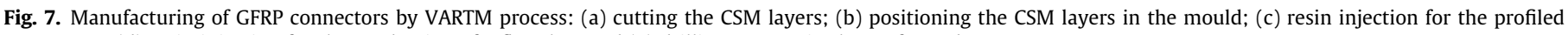
connectors; (d) resin injection for the production of a flat plate and (e) drilling process in the perforated connectors.

the dispersion of results was low as shown in Table 3. As shown in Fig. 6, the responses of all laminates are not exactly linear in the loaded directions. This behaviour was expected due the high content of fibres transversally positioned to the load direction. From the results, it should be also noted that the laminates comprising longer fibres ( $\mathrm{C} 1$ and $\mathrm{C} 3$ ) presented higher ultimate tensile strength and strain (see Table 3 ) than the similar composites comprising CSM laminates (C2 and C4, respectively).

Among the types of GFRP investigated, the CSM laminate (C2) was the material chosen to produce the connectors used in the pull-out experimental program due to its relative low cost, production simplicity and satisfactory mechanical properties.

The VARTM was the adopted process to the production of the connectors. In this process the CSM fabric was cut (Fig. 7a), stacked and positioned in the mould (Fig. 7b). Then, the set was covered by a vacuum bag closed by sealant tape. The tubes, a resin inlet connected to the resin supply and a vacuum line connected to a vacuum pump, were laid above the stacked fabric at the edges along the length of the mould (Fig. 7c). The vacuum pump was turned on and the resin was allowed to flow until complete impregnation was achieved (Fig. 7d). The piece was cured at room temperature and, once hardened, the parts were cut and drilled to obtain the final geometry of the connector (Fig. 7e).

To produce the GFRP profiles, two "L-shaped" steel plates were adopted as mould to keep the desired geometry (see Fig. 7b). The web has exactly the same architecture of the perforated connectors, while the flanges were produced through bending half of the reinforcement sheets for each side and placing additional continuous sheets to achieve the same amount of fibres and thickness of the web (see Fig. 7b).

\subsection{GFRP to SFRSCC connections}

A challenge on the development of this sandwich system is the coupling of the GFRP connectors and the thin layers of SFRSCC.
These connections influence the overall behaviour of the sandwich panel in terms of strength, stiffness and deformation capacity. Thus, they should be designed to guarantee enough strength and a rather ductile behaviour. So, to accurately predict the ultimate behaviour of a sandwich panel and to ensure that the GFRP connectors remain far from failure, the response of the connectors must be well determined.

The feasibility of using the proposed connectors as mechanical shear connectors was experimentally accessed via a series of pull-out tests where the failure modes, load capacity, stiffness and deformation capacity of the connections were analysed. In this study, the pull-out experiments were conducted on the three types of connectors proposed in Section 2.2.

The configurations adopted for the simply perforated connectors were strongly influenced by the constraints imposed by the small thickness of SFRSCC block (Fig. 8a). The thickness of the SFRSCC layer of $60 \mathrm{~mm}$ was determined from finite element numerical simulations (described in the companion paper [18]), and considering practical manufacturing restrictions indicated by the precasting company that is partner of the present research project. The distance between the connector and the bottom surface of the SFRSCC layer was kept constant and equal to $15 \mathrm{~mm}$ to enable the passage of SFRSCC in these regions during the casting process. Two different types of perforated plates were investigated: $\mathrm{L} 4 \mathrm{C}$ and L3E. The L4C connector, shown in Fig. 8b, includes circular holes of $30 \mathrm{~mm}$ diameter $(d)$, centres spaced $2 \cdot d$ from each other. A connector with elongated holes (L3E) was also investigated. The idea behind this geometry is to try to improve the load capacity of the connection by increasing the sectional area of SFRSCC dowels (see Fig. 8c).

In the case of the profiled embedded connector (TEM), in order to prevent problems during the casting process, enabling the SFRSCC to flow and fill all spaces within the formwork, the distance between the bottom part of the connector and the form was equal to $20 \mathrm{~mm}$ (Fig. 8d and e). The profiled connectors embedded (TEM) 
and adhesively bonded (TAB) had the same geometry, both having a flange width of $100 \mathrm{~mm}$ (see Fig. $8 \mathrm{~d}$ and f).

In the case of the embedded connectors (L4C, L3E and TEM), they were previously positioned in the steel formwork in order to guarantee their alignment with the SFRSCC block and the prescribed concrete cover (Fig. 9a). Then, the SFRSCC blocks were first poured from the end of the mould, allowing the concrete to flow through the holes of the perforated connectors, as shown in Fig. 9b, or behind the connector in the case of TEM. All the specimens were cast in the horizontal position to simulate the casting

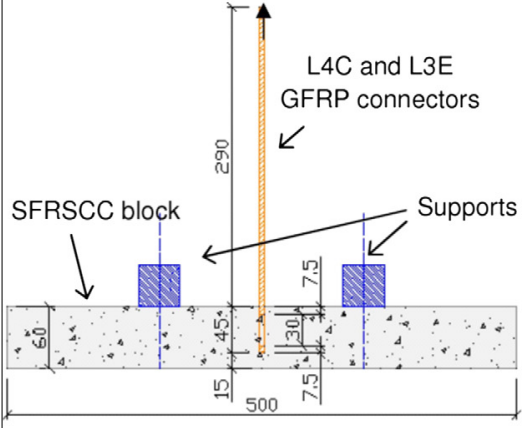

(a)

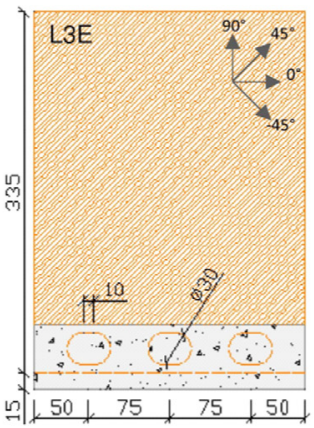

(c)

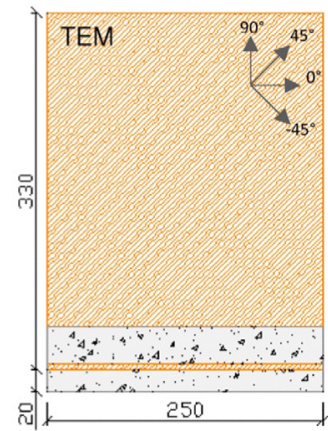

(e)

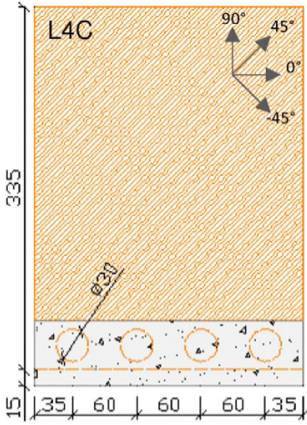

(b)

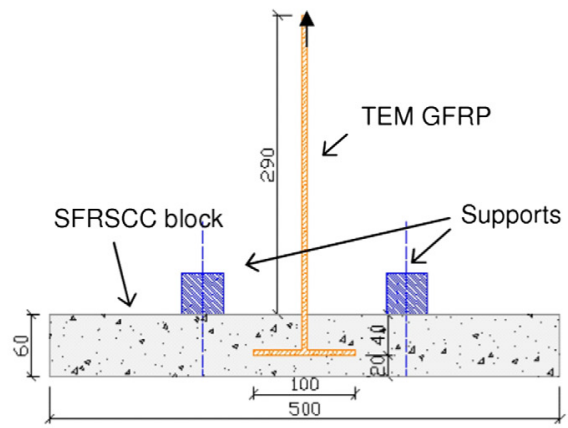

(d)

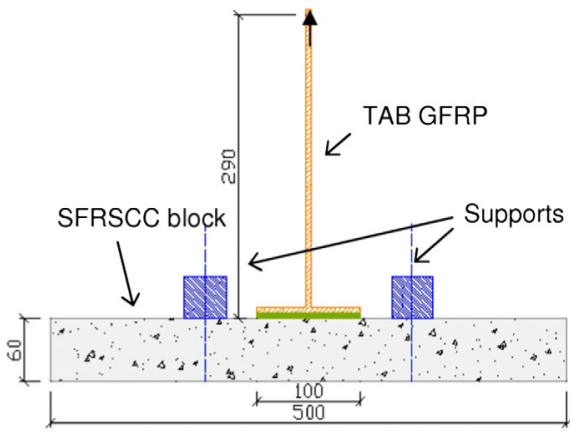

(f)

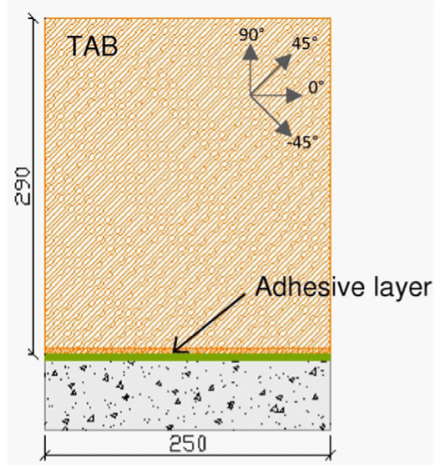

(g)

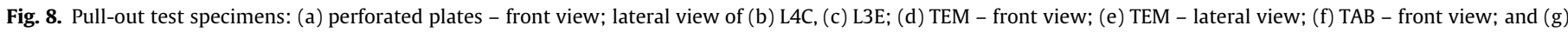
$\mathrm{TAB}$ - lateral view (units in millimetres). 


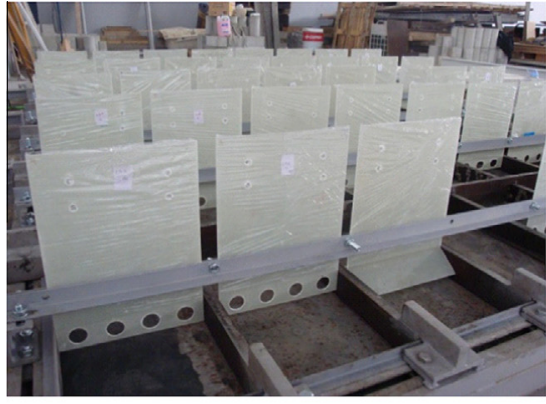

(a)

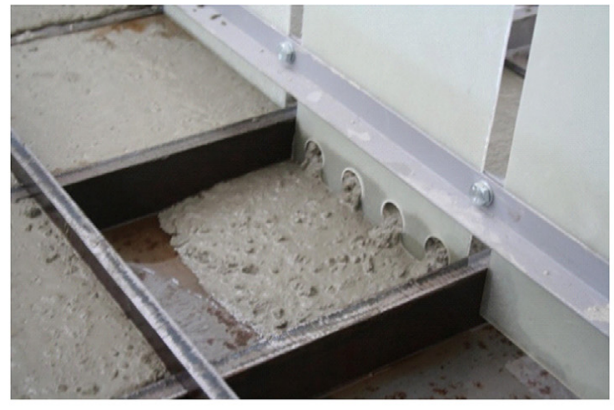

(b)

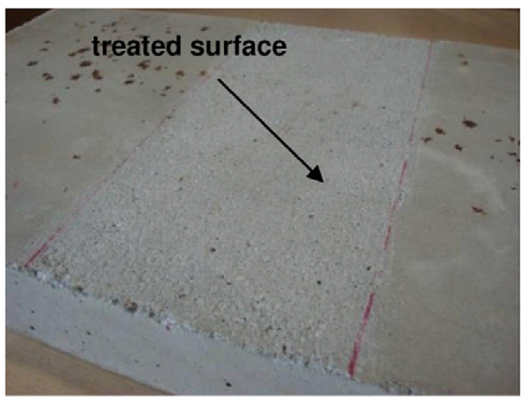

(c)

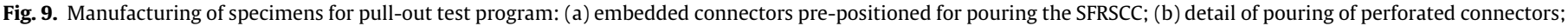
and (c) treated surface for the adhesively bonded connections.

conditions of the panels' production. SFRSCC blocks without connectors were also produced for the adhesively bonded connectors. The specimens were cured in ambient conditions for 46-60 days until the testing dates.

In the case of adhesively bonded connection (TAB), the GFRP profiles were bonded to the SFRSCC blocks using a two-component epoxy adhesive [35]. According to the data provided by the manufacturer, the adhesive strength of this resin applied on concrete after 3 days of curing at $20^{\circ} \mathrm{C}$ is, at least, $3.0 \mathrm{MPa}$. To improve the bonding conditions, the concrete surface was treated by removing the superficial cement paste layer with a needle gun scaler before applying the resin (Fig. 9c). The GFRP profiles were glued to the SFRSCC blocks at 54 days of age. Immediately after bonding, the specimens were kept in a room with temperature of $20^{\circ} \mathrm{C}$ and humidity of $60 \%$ for 7 days up to the test.

Three specimens per type of connector were produced using the L4C and TEM connectors, whereas two specimens per type of connector were produced using the $\mathrm{L} 3 \mathrm{E}$ and $\mathrm{TAB}$ connectors.

\subsubsection{Experimental setup}

The test setup adopted is shown in Fig. 10, which includes: a servo-hydraulic machine, $50 \mathrm{kN}$ load cell, grips, supports, displacement transducers and electronic data acquisition unit. The vertical load was applied at the top extremity of the GFRP by using grips that distribute the load on a $150 \mathrm{~mm} \times 200 \mathrm{~mm}$ area of the GFRP surface. The supports consisted on a pair of steel bars with a square

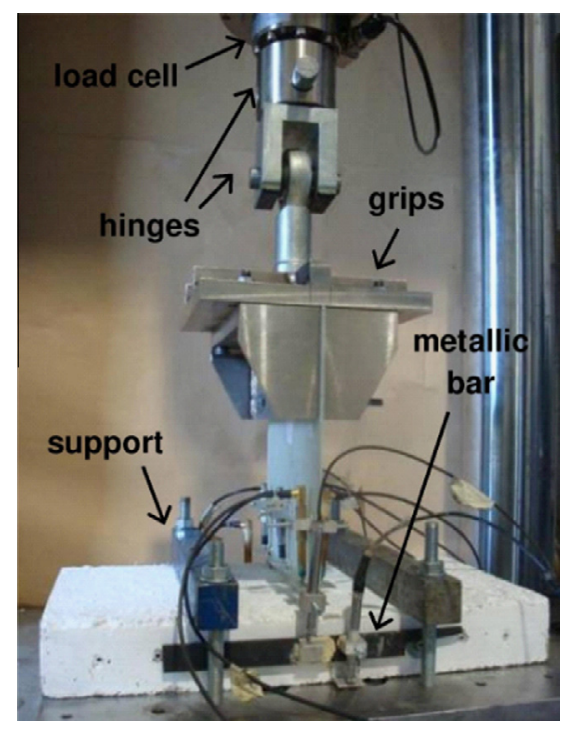

Fig. 10. Pull-out test setup: overall view. cross section of $40 \mathrm{~mm}$ edge and $500 \mathrm{~mm}$ long forming two linear supports parallel to the connector spaced of $200 \mathrm{~mm}$ from each other. These bars were fixed to the rigid base of the test machine through 4 steel threaded $\Phi 14$ rods positioned in the ends of the bars, providing the necessary reaction.

To measure the strains in the zone of the GFRP between the SFRSCC block and the grips, 6 displacement transducers (LVDT) were adopted, each one applied between two points of the lateral

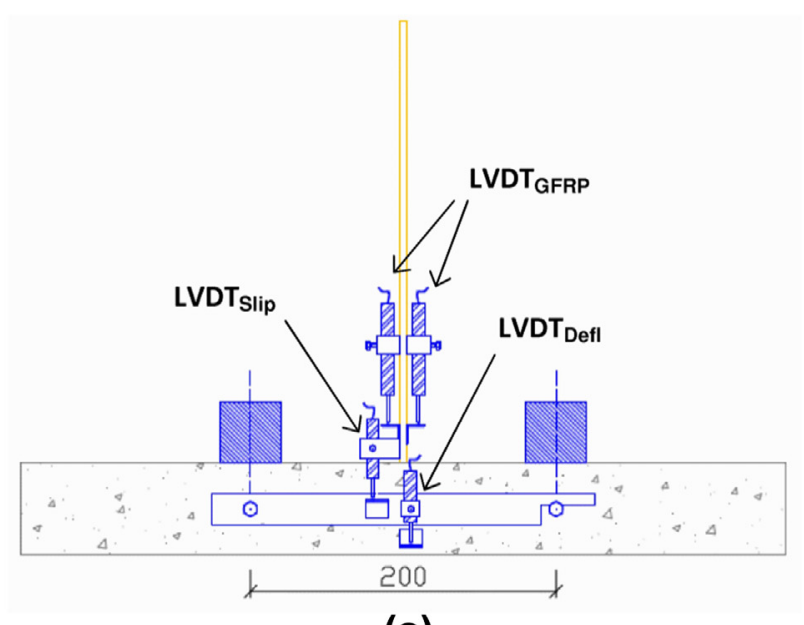

(a)

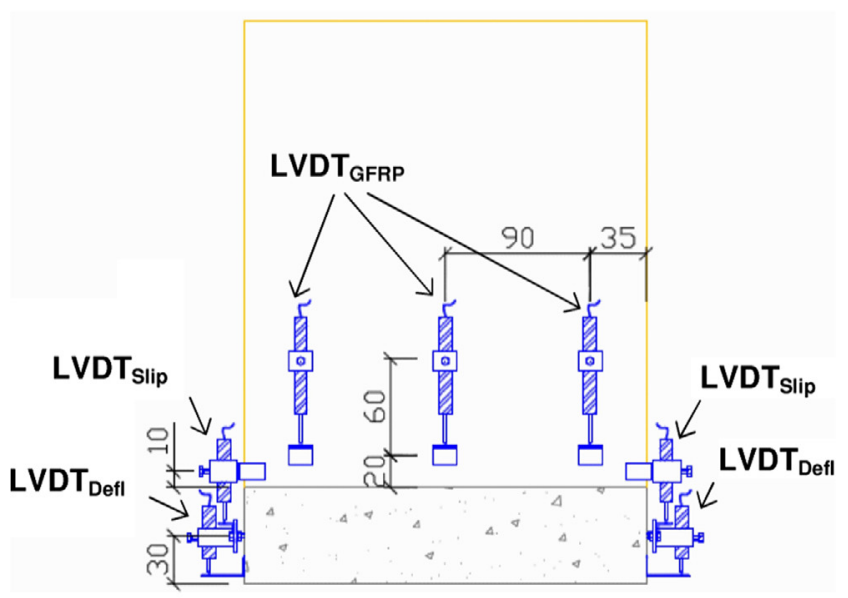

(b)

Fig. 11. Details of the instrumentation: (a) front view and (b) side view (units in $\mathrm{mm})$. 


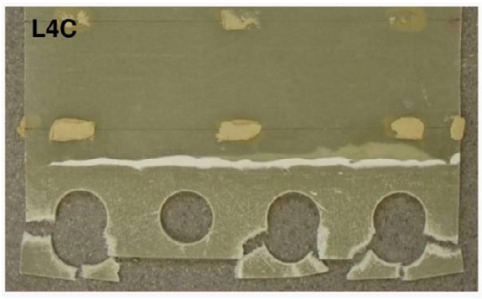

(a)

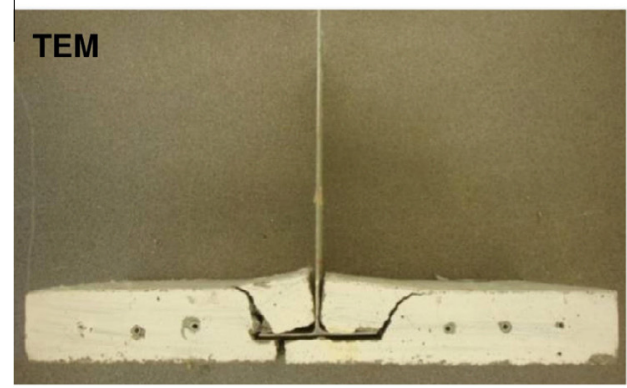

(d)

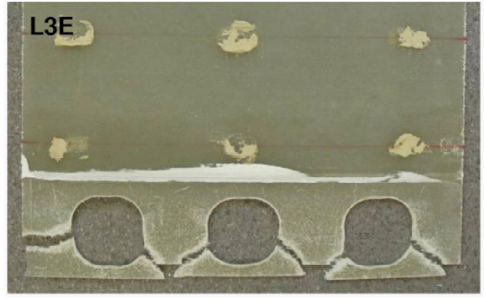

(b)

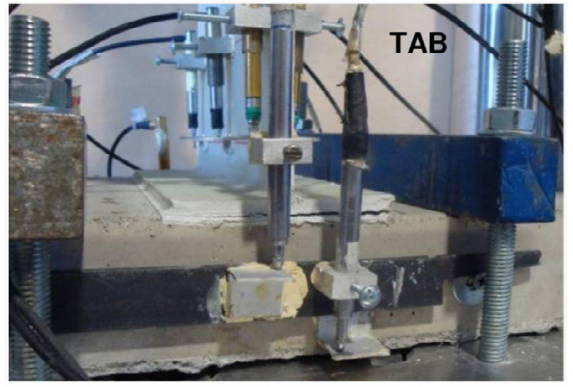

(e)

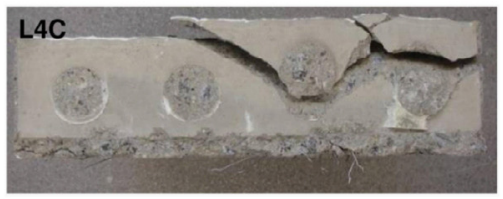

(c)

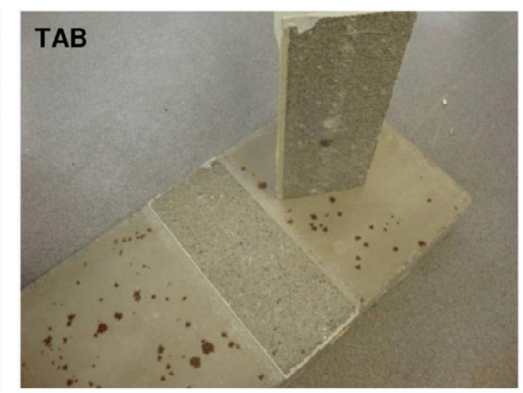

(f)

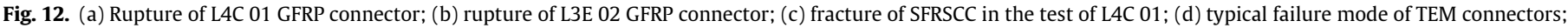
(e) debonding of TAB connector during test; and (f) typical appearance of the failure surfaces of TAB connectors.

surface of the GFRP (LVDTGFRP), as shown in Fig. 11. The strains in this zone of the GFRP were obtained by considering the relative displacement between these points with a reference length of $60 \mathrm{~mm}$ (Fig. 11b). In order to assure the validity of these measurements, in one of the tests the readings of the extensions in GFRP computed through readings taken with LVDT $_{\text {GFRP }}$ were compared with values obtained using strain gauges positioned between the two points of reference adopted for each LVDT. The results indicated that the readings made by LVDT accompanied satisfactory the readings obtained with strain gauges. The largest error found for the maximum deformation in the GFRP obtained by means of the two methods was $6.0 \%$.

The slip between the GFRP and the concrete block was measured in the front and rear side of specimen by supporting one transducer in the GFRP surface nearby the concrete top surface $\left(\mathrm{LVDT}_{\text {Slip }}\right.$ ) (see Fig. 11). A metallic bar was adopted as reference point to measure the slip between GFRP and concrete, since this bar was fixed on two points of the concrete block where the concrete deformability is considered negligible (Fig. 11a). Another transducer was fixed to this bar to measure the midspan deflection of the concrete block ( LVDT $_{\text {Deff }}$ ), and this value was subtracted from the measures of the transducer fixed to the GFRP in order to obtain the relative slip between the GFRP and the concrete block. All the specimens were tested under monotonic loading at a constant displacement rate of $0.03 \mathrm{~mm} / \mathrm{s}$.

\subsubsection{Pull-out tests: results and discussion}

The failure mechanism observed in all perforated plate connectors (L4C and L3E) was associated to the rupture of the GFRP in the vicinity of the holes (Fig. 12a and b). For these connectors, the rupture often happened in a sequence of abrupt decays of load, indicating that the failure of the GFRP in the vicinity of each hole occurred in different stages of the test (see Fig. 14a and b). This may be a consequence of different stiffness amongst the concrete dowels, localised imperfections in the connector and/or non-uniform distribution of stresses within the GFRP. However, all the perforated connectors show a significant residual load capacity after maximum load. Inspecting the GFRP/SFRSCC contact surfaces after the tests, it was noticed that these surfaces were scratched, indicating the existence of some adherence/friction between these materials. Moreover, most of the specimens with perforated connectors presented fracture surfaces in the SFRSCC, formed by the tensile forces transferred from the GFRP connector to the surrounding SFRSCC (see Fig. 12c).

In the case of the TEM and TAB connections, naked eye observations led to the conclusion that the GFRP connectors were intact at the end of the tests. For the TEM connector, the fracture surfaces in the concrete block appeared suddenly, forming two concrete prisms that progressively lost the contact with the GFRP connector (Fig. 12d). The lateral cracks of these prisms propagated from the extremities of the connector to the top surface of the SFRSCC block with an inclination of about $45^{\circ}$. In the case of TAB connections, the failure started from an extremity of the connector and rapidly progressed up to the complete debonding of the GFRP connector (Fig. 12e), which was accompanied of a sudden decay of the load carrying capacity of the connection. This type of failure was already expected because the ultimate failure in the adhesively bonded connections generally occurs in a brittle and sudden manner [36]. It was observed in both TAB specimens that failure occurred within the concrete block, by tearing off a thin layer of matrix (Fig. 12f), showing the effectiveness of the adhesive and of the treatment executed in the concrete surface bonded to the GFRP connector. This indicates that the weaker link in this connection system was the concrete substrate.

Fig. 13a-d present load per unit length vs strain in the GFRP connectors curves, until the peak load. The curves shown in these graphs are representative of the behaviour of the type of connector. Concerning the occurrence of bending in GFRP, this is a problem inherent to the support conditions adopted in the tests. As the SFRSCC block is not attached to a hinged basis, any eccentricity can cause bending in GFRP. However, the results monitored through the LVDT $_{\text {GFRP }}$ showed that, although some bending was verified in the specimens, it was never in an extent to jeopardise the validity of the results.

Fig. 14a-e show load vs average slip between GFRP connectors and SFRSCC block. The maximum value of the average strain in the $\operatorname{GFRP}\left(\varepsilon_{G F R E \text {,max }}\right)$, the failure load $\left(q_{u}\right)$ and the corresponding average slip $\left(\delta_{u}\right)$ are shown in Table 4 . Among the several types of tested 


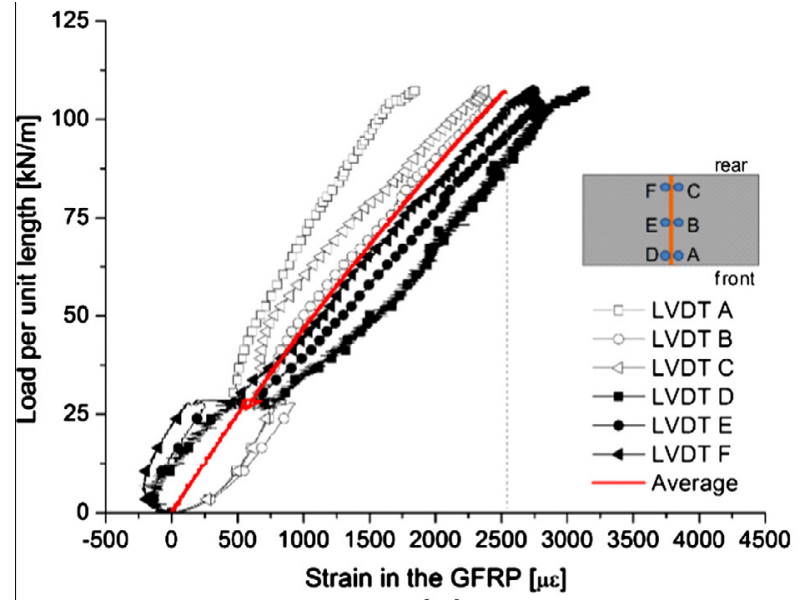

(a)

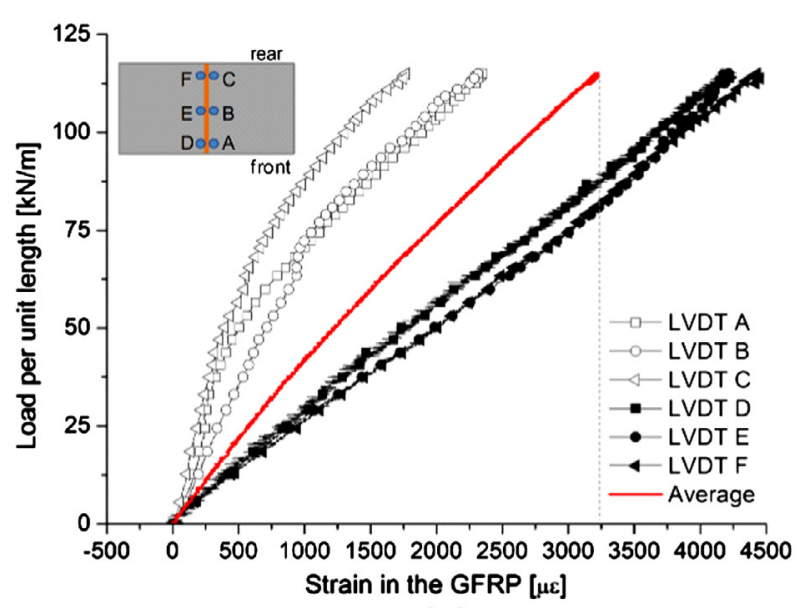

(c)

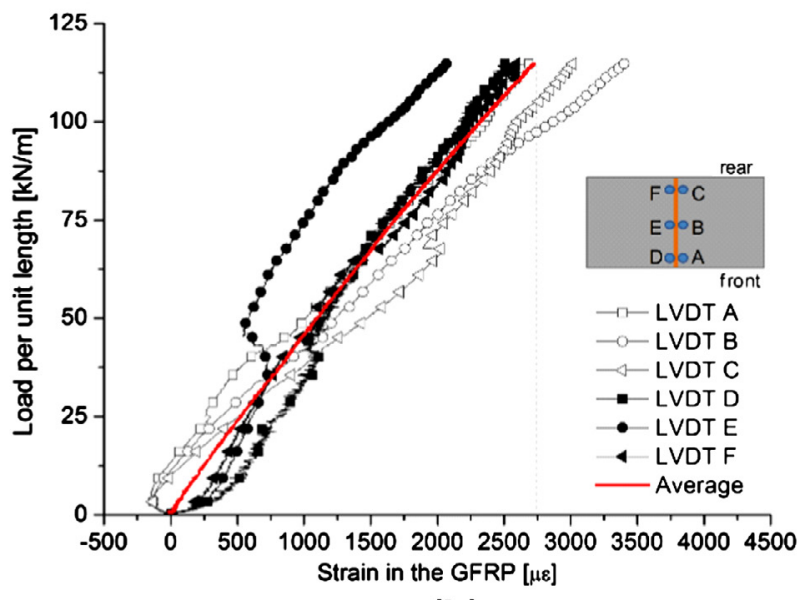

(b)

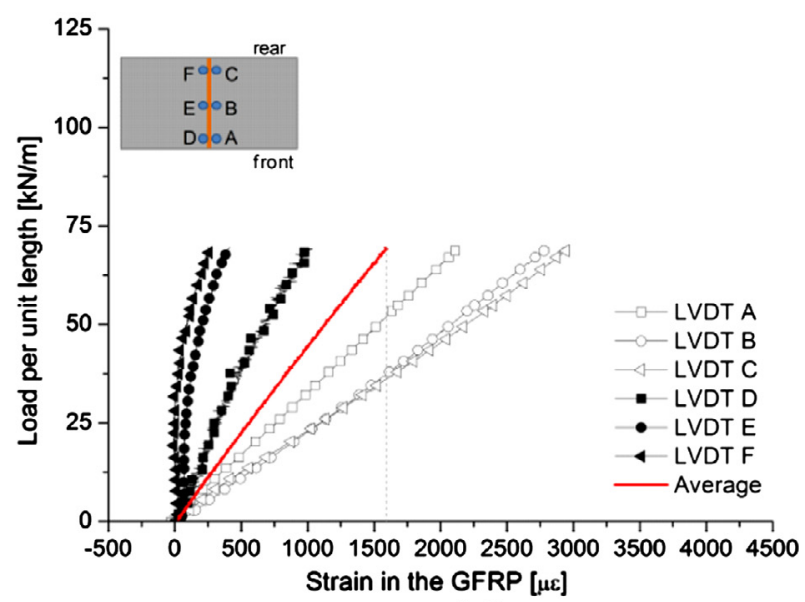

(d)

Fig. 13. Strains in the GFRP until the peak load for the specimens: (a) L4C 01; (b) L3E 01; (c) TEM 01 ; and (d) TAB 02.

connectors, there was a fairly low dispersion of results as shown in Table 4 (exception for L3E). Therefore, even though the number of specimens of each type is not enough to ensure a proper statistical treatment of results, it is nonetheless possible to perform a comparative evaluation of the performance of the tested solutions.

The strains measured in the GFRP were much lower than the ultimate strains recorded in the GFRP direct tensile specimens for the CSM laminate (see Table 3), with average values in the interval between $1455 \mu \varepsilon$ and $4610 \mu \varepsilon$.

Comparing the values of the failure loads, it can be concluded that the perforated and TEM connectors developed similar load capacity, significantly above the one presented by the TAB connectors ( $64 \%$ of the mean load capacity of the other connectors). The failure load for all the perforated connectors is mainly limited by the capacity of the GFRP sections bellow and between the holes (Fig. 12a and b). In the case of TEM connectors, the reduced embedment depth imposed by the thickness of the SFRSCC layer appears to have limited their load capacity.

The average slips corresponding to the failure loads were higher in the embedded connectors, while TAB connectors presented a much lower average slip $(0.04 \mathrm{~mm})$, which corresponds to the deformability of the adhesive layer and fracture propagation through the thin layer of cement paste. In the perforated connectors, the failure occurred in a relatively ductile way for all the connections due to the sequential failure of the GFRP in the vicinity of holes. In the TEM connectors the rupture was also ductile, but presented a rapid progress of crack surfaces in the SFRSCC block followed by an abrupt decay of the load capacity (Fig. 12e). The adhesively bonded connector presented the most brittle failure mode, with an incipient nonlinear branch before the peak load.

The relatively high post-peak residual capacity of L and TEM connectors is based on the following reasons: In the L type connectors exist an internal support redundancy of the connector, since the rupture of one section does not conduct to the failure of the connector (see Fig. 12a-c were it is visible the formation of several fracture failures in the L connectors). The successive occurrence of fracture failures in the vicinity of the holes provoked a drop on the load carrying capacity, which was followed by an increase of the slip of the connector. During this process, fracture cones were also formed in the SFRSCC and the reinforcement mechanisms of fibres bridging these fracture surfaces have also contributed for the postpeak load carrying capacity of the L type connectors.

In the TEM connector system, no fractures occurred in the GFRP, and the nonlinear part of the response of this system is justified by the loss of contact between GFRP connector and surrounding SFRSCC, as well as crack propagation in the SFRSCC. The peak load was almost sustained for a slip variation of about $2 \mathrm{~mm}$, due to the contribution of fibre reinforcement mechanisms bridging the 


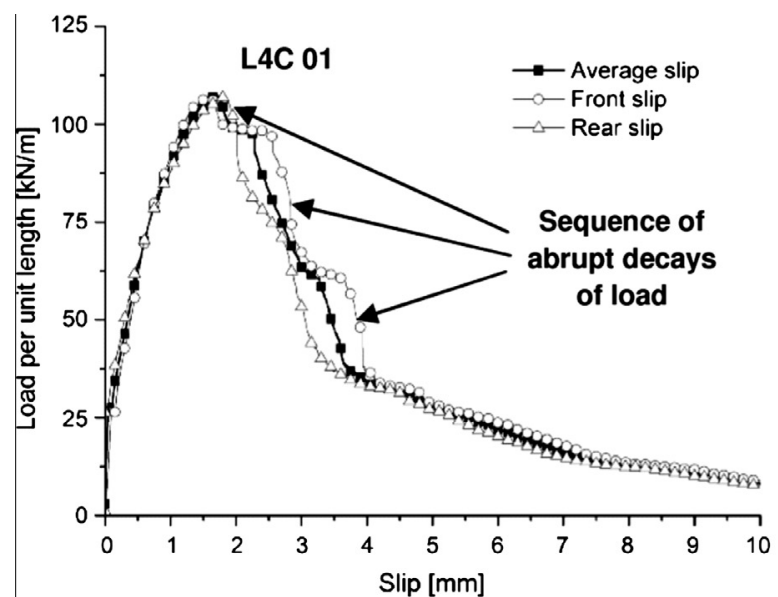

(a)

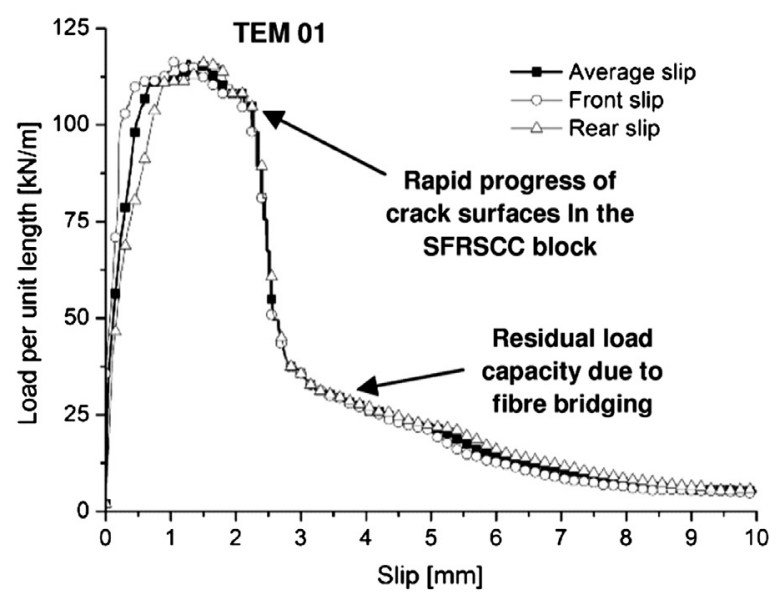

(c)

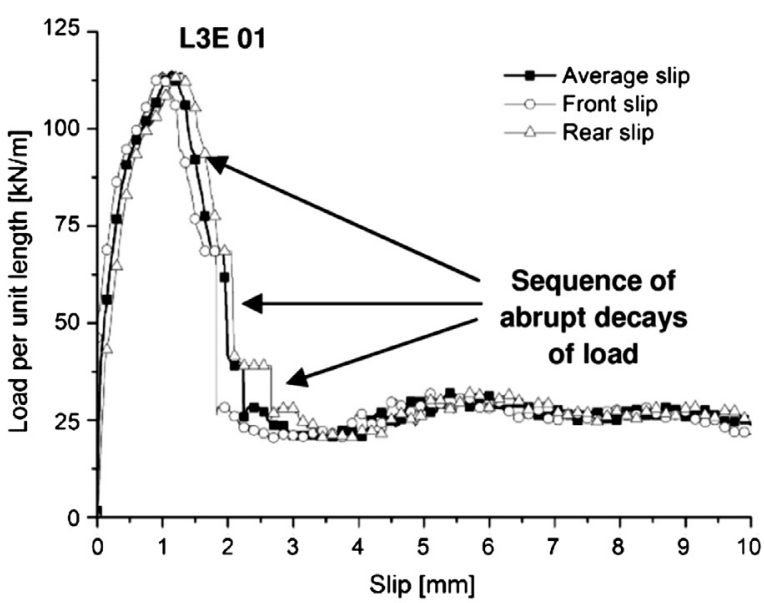

(b)

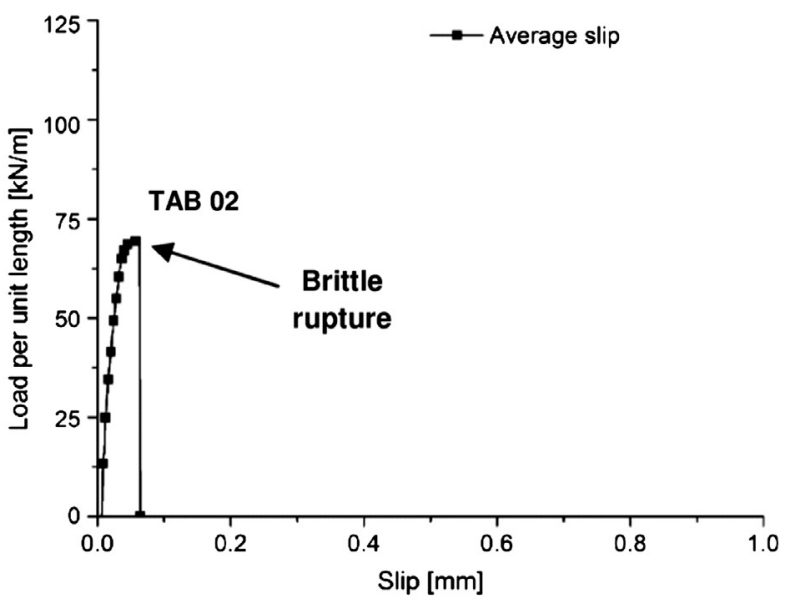

(d)

Fig. 14. Representative load-slip responses for the connectors: (a) L4C; (b) L3E; (c) TEM and (d) TAB.

Table 4

Individual values of failure loads per length of connector $\left(q_{u}\right)$, average slip $\left(\delta_{u}\right)$ and maximum strain in the GFRP $\left(\varepsilon_{G F R P, \text { max }}\right)$.

\begin{tabular}{|c|c|c|c|c|c|}
\hline Specimen & & & $\varepsilon_{G F R P, \max }(\mu \varepsilon)$ & $q_{u}(\mathrm{kN} / \mathrm{m})$ & $\delta_{u}(\mathrm{~mm})$ \\
\hline \multirow[t]{8}{*}{ Embedded connections } & Perforated plates & L4C 01 & 2525 & 107.32 & 1.719 \\
\hline & & L4C 02 & 2515 & 98.58 & 1.441 \\
\hline & & L4C 03 & 2781 & 113.92 & 0.940 \\
\hline & & L3E 01 & 2729 & 114.80 & 1.144 \\
\hline & & L3E 02 & 2063 & 95.84 & 1.226 \\
\hline & Profiled connector & TEM 01 & 3247 & 116.72 & 1.288 \\
\hline & & TEM 02 & 3480 & 112.58 & 4.340 \\
\hline & & TEM 03 & 4610 & 106.05 & 2.650 \\
\hline \multirow[t]{2}{*}{ Adhesively bonded connection } & & TAB 01 & 1455 & 70.25 & 0.013 \\
\hline & & ТAB 02 & 1556 & 69.44 & 0.062 \\
\hline
\end{tabular}

formed cracks during the first stages of crack propagation. With the increase of the width in these cracks, the fibre reinforcement effectiveness decreases (see Fig. 4) and an abrupt load decay has occurred, and finally a stage of smooth load decay with the increase of slip is visible, which is supported by the frictional resisting phase of the fibre reinforcement mechanisms (for a relatively large values of crack width). At the initiation of the abrupt load decay the slip is higher than $2 \mathrm{~mm}$, which is a relatively high value, even when compared with the bond behaviour of GFRP bars surrounded by SFRSCC [37]. This level of slip is an indicator of ductility in the response of this type of connection. The smooth load decay in the last phase of the response of the TEM connector, that started at a load level of at about $30 \%$ of the peak load, is also an indicator of a ductile response of this type of connection.

\section{Conclusions}

In this study an innovative sandwich panel comprising steel fibre reinforced self-compacting concrete (SFRSCC) layers and glass fibre reinforced polymer (GFRP) laminate connectors was proposed 
as the basic construction unit for prefabricated modular houses. Special focus was given to the behaviour of SFRSCC/GFRP connections by performing experimental programs.

In the first part of the experimental program, the possibility of using different types of GFRPs as material for the connectors was investigated. The relevant properties of these materials were evaluated under direct tensile tests, and their tensile strength, stiffness and stress-strain relationship were compared. The chopped strand mat (CSM) laminate was the material chosen for the connectors considering mechanical performance and cost competitiveness.

After choosing the GFRP to be employed, different types of connectors were produced and the connections to the SFRSCC were materialised by adopting specimens with the geometry representative of the dimensions of the sandwich panels. Four types of connections were studied, comprising three embedded solutions and one adhesively bonded alternative. The behaviour of these connections was evaluated by means of pull-out tests. From the results obtained, it can be concluded that, despite the restrictions imposed by the relatively small thickness of the SFRSCC layers, the embedded connectors provided the highest load carrying capacity. All the embedded solutions presented a significant ductility after peak load. It is important to emphasise the good performance of the perforated connectors that, despite their simplicity, presented a relatively high load capacity and an appreciable residual resistance.

Among the studied connectors, the perforated plates proved to be particularly attractive because they are the simplest of executing, the most economic in terms of materials consumption, provide the smallest obstacles for the casting process of SFRSCC. The openings along the connectors' length proved to have the desired structural behaviour, adding significant load capacity to the connection.

In the companion paper that follows, the maximum tensile stresses in the GFRP connectors will be estimated from numerical investigation by considering the functioning of the sandwich panel system integrated in the modular houses to be developed, in order to have a better knowledge about the material requirements for these connectors.

\section{Acknowledgements}

This work is part of the research project QREN number 5387, LEGOUSE, involving the companies Mota-Engil, CiviTest, the ISISE/University of Minho and PIEP. The first author would like to thank the FCT for the financial support through the PhD Grant SFRH/BD/64415/2009. The authors also thank the collaboration of the following companies: Maccaferri and RADMIX ${ }^{\mathrm{TM}}$ for supplying the fibres, Secil and SIKA for providing the cement and the superplasticizers, respectively, and S\&P - Clever Reinforcement Ibérica for supplying the epoxy adhesive.

\section{References}

[1] PCI Committee on Precast Sandwich Wall Panels. State-of-the-art of precast/ prestressed sandwich wall panels. Precast/Prestressed Concr Inst J 2011;56:131-75.

[2] Pessiki S, Mlynarczyk A. Experimental evaluation of the composite behavior of precast concrete sandwich wall panels. J Prescast/Prestress Concr Inst 2003:48:54-71.

[3] Bush TD, Wu Z. Flexural analysis of prestressed concrete sandwich panels with truss connectors. Precast/Prestress Concr Inst J 1998;43:76-86.

[4] Salmon DC, Einea A, Tadros MK, Culp TD. Full scale testing of precast concrete sandwich panels. ACI Struct J 1997;94:354-62.

[5] Benayoune A, Samad AAA, Trikha DN, Ali AAA, Ellinna SHM. Flexural behaviour of pre-cast concrete sandwich composite panel - experimental and theoretical investigations. J Construct Build Mater 2008;22:580-92.

[6] Lee B-J, Pessiki S. Thermal performance evaluation of precast concrete threewythe sandwich wall panels. Energy Build 2006;38:1006-14
[7] McCall WC. Thermal properties of sandwich panels. Concr Int: Des Construct 1985:7:34-41.

[8] Frankl BA. Structural behabior of insulated precast prestressed concrete sandwich panel reinforced with CFRP grid. Thesis, Civil Engineering, North Carolina State University; 2008.

[9] Lucier G, Rizkalla SH, Hassan T. Thermally efficient precast concrete sandwich load bearing wall panels reinforced with CFRP. In: 3rd Fib international congress. Washington DC, USA; 2010 [paper on CD].

[10] Prisco M, Plizzari G, Vandewalle L. Fibre reinforced concrete: new design perspectives. Mater Struct 2009;42:1261-81.

[11] Nemegeer D, Vanbrabant J, Stang H. Brite-euram program on steel fibre concrete, durability corrosion resistance of cracked fibre-reinforced concrete. In: Schnütgen B, Vandewalle L, editors. Test and design methods for steel fibre reinforced concrete-background and experiences RILEM technical committee 162. TDF Workshop, Proceedings Pro 31; 2003. p. 47-66.

[12] Bernard ES. Durability of fibre-reinforced shotcrete. In: Shotcrete: more engineering developments. Queensland, Australia: Taylor and Francis; 2004.

[13] Einea A, Salmon DC, Tadros MK, Culp TD. A new structurally and thermally efficient precast sandwich panel system. Precast/Prestress Concr Inst J 1994:39:90-101.

[14] Pantelides CP, Surapaneni R, Reaveley LD. Structural performance of hybrid GFRP/steel concrete sandwich panels. J Compos Construct 2008;12:570-6.

[15] Woltman GD, Tomlinson DG, Fam A. A comparative study of various FRP shear connectors for sandwich concrete walls. In: CICE 2010 - the 5th international conference on FRP composites in civil engineering. Beijing, China; 2010.

[16] Naito C, Hoemann J, Beacraft M, Bewick B. Performance and characterization of shear ties for use in insulated precast concrete sandwich wall panels. J Struct Eng 2012;138:52-61.

[17] Barros JAO, Pereira ENB, Santos S. Lightweight panels of steel fiber-reinforced self-compacting concrete. J Mater Civil Eng 2007;19:295-304.

[18] Lameiras R, Barros J, Azenha M, Valente IB. Development of sandwich panels combining fibre reinforced concrete layers and fibre reinforced polymer connectors. Part II: Evaluation of mechanical behaviour. Compos Struct 2013;105:460-70

[19] Elliott KS. Precast concrete structures. Oxford: Butterworth-Heinemann; 2002.

[20] Engström B, Alexander S, Cholewicki A, Chefdebien AD, Bella BD, Elliott KS, et al. Fib Bulletin 43: Structural connections for precast concrete buildings. fib - fédération internationale du béton; 2008.

[21] Valente I, Cruz PJS. Experimental analysis of Perfobond shear connection between steel and lightweight concrete. J Construct Steel Res 2004;60:465-79.

[22] Cho K, Park S, Kim S, Cho J-R, Kim B-S. Shear connection system and performance evaluation of FRP-concrete composite deck. KSCE J Civil Eng 2010;14:855-65.

[23] Keller T, Schaumann E, Vallée T. Flexural behavior of a hybrid FRP and lightweight concrete sandwich bridge deck. Compos Part A: Appl Sci Manuf 2007;38:879-89.

[24] Bakis CE, Bank LC, Brown VL, Cosenza E, Davalos JF, Lesko JJ, et al. Fiberreinforced polymer composites for construction - state-of-the-art review. J Compos Construct 2002;6:73-87.

[25] Deskovic N, Triantafillou TC, Meier U. Innovative design of FRP combined with concrete: short-term behavior. J Struct Eng 1995;121:1069-78.

[26] Kim YJ, Fam A. Numerical analysis of pultruded GFRP box girders supporting adhesively-bonded concrete deck in flexure. Eng Struct 2011;33:3527-36.

[27] Luo Y, Li A, Kang Z. Parametric study of bonded steel-concrete composite beams by using finite element analysis. Eng Struct 2012;34:40-51.

[28] Pereira E, Barros J, Ribeiro A, Camões A. Post-cracking behaviour of selfcompacting steel fibre reinforced concrete. In: 6th International RILEM symposium on fibre reinforced concrete - BEFIB 2004. Varenna; 2004.

[29] CEN, EN 12390-3. Testing hardened concrete - part 3: compressive strength of test specimens; 2001.

[30] LNEC. E397 concrete: determination of the modulus of elasticity in compression. Lisbon; 1993 [Portuguese].

[31] RILEM TC 162-TDF. Bending test. Mater Struct 2002;35:579-82.

[32] Lameiras RM, Barros J, Azenha M, Valente I. Sandwich structural panels comprising thin-walled steel fibre reinforced self-compacting concrete (SFRSCC) and fibre reinforced polymer (FRP) connectors. In: 8th RILEM international symposium on fibre reinforced concrete (BEFIB 2012). Guimarães, Portugal; 2012.

[33] Williams C, Summerscales J, Grove S. Resin infusion under flexible tooling (RIFT): a review. Compos Part A: Appl Sci Manuf 1996;27:517-24.

[34] ASTM Standard D 3039/D 3039M. Tensile Properties of polymer matrix composite materials. West Conshohocken, PA: ASTM International; 2008.

[35] S\&P. Technical Data Sheet: S\&P Resin 220 epoxy adhesive; 2012.

[36] Jiang X, Kolstein MH, Bijlaard FSK. Study on mechanical behaviors of FRP-tosteel adhesively-bonded joint under tensile loading. Compos Struct 2013;98:192-201.

[37] Mazaheripour H, Barros J, Sena-Cruz J, Soltanzadeh F. Analytical bond model for GFRP bars to steel fiber reinforced self-compacting concrete. J Compos Construct (ASCE); 2013 [Preview Manuscript]. 